\title{
Adaptations to physical exercise in the lipid profile and the cardiovascular health of morbidly obese
}

\author{
Pedro Delgado-Floody', Felipe Caamaño-Navarrete ${ }^{2}$, Daniel Jerez-Mayorga ${ }^{3}$, Cristian Martínez-Salazar', \\ Felipe García-Pinillos ${ }^{1}$ and Pedro Latorre-Román ${ }^{4}$ \\ ${ }^{1}$ Department of Physical Education, Universidad de La Frontera, Temuco; ${ }^{2}$ Pedagogy in Physical Education Degree, Faculty of Education, \\ Universidad Católica de Temuco, Temuco; ${ }^{3}$ Faculty of Rehabilitation Sciences, Universidad Andres Bello, Santiago, Chile; ${ }^{4}$ Department of Musical, \\ Plastic and Body Expression Didactics, Universidad de Jaén, Jaén, Spain
}

\begin{abstract}
Objective: To assess the effects of a physical exercise program on the lipid profile, weight status and the cardiovascular health of obese candidates for bariatric surgery. Method: 22 morbidly obese patients participated in a 6-month physical exercise program. 16 formed the adherent group (attendance $\geq 80 \%$; age: $37.81 \pm 11.90$ years) and six the non-adherent group (attendance < 80\%; age: $45.83 \pm 14.23$ years). Before and $72 \mathrm{~h}$ after the last session were evaluated: weight, body mass index (BMI), contour waist, blood pressure, fasting, cardio respiratory fitness, cholesterol and triglycerides. Results: Weight, BMI and WC showed significant changes $(p<0.05)$ in both groups, with the results of the adherent group being better. In the adherent group, cardiorespiratory capacity $(p=0.001)$ was also increased, while diastolic pressure $(p=0.011)$, basal glycemia $(p=0.021)$ and triglycerides decreased significantly $(p<0.001)$. The non-adherent group did not present significant changes in these variables $(p \geq 0.05)$. Conclusions: The intervention was feasible to perform without negative effects for the participants, and it is possible to recommend improving the cardiovascular health of these of patients.
\end{abstract}

KEY WORDS: Obesity. Morbid obesity. Physical exercise.

\section{Introduction}

Obesity promotes a series of cellular processes that attenuate the leptin signaling, thus developing "cellular leptin resistance" and increasing the degree of weight gain ${ }^{1}$, and playing a role in the regulation of body fat deposits and blood glucose values ${ }^{2}$. It is considered to be one of the currently most important and prevalent non-transmittable diseases ${ }^{3}$, and it is associated with risk factors for cardiovascular disease $^{4,5}$, as well as with some types of cancer ${ }^{6}$; it affects the immune response ${ }^{7}$, drives to a higher state of morbidity and mortality ${ }^{8}$, and produces a considerable decrease of life expectancy 9 .

Morbid obesity is a chronic condition with serious consequences on health owing to the associated comorbidity, and is a risk factor that triggers metabolic syndrome and cardiovascular diseas $\mathrm{e}^{10}$. In Chile, obesity has doubled in the past few decades, and morbid obesity, in specific, increased from 148,000 people in the year 2003 to 300,000 in the year $2010^{11}$, generating elevated costs for public health.

For the treatment of morbid obesity, bariatric surgery is a technique by means of which great improvement in patients' anthropometric parameters, cardiovascular risk factors and quality of life is attained ${ }^{12}$; however, it is important to consider that higher preoperative weight might increase morbidity and mortality ${ }^{13}$, which generates the need for preoperative treatments that improve this condition and adapt the patients to subsequent stages. There is evidence that interval-wise physical exercise and nutritional counseling improve these

\author{
Correspondence: \\ Pedro Delgado-Floody \\ Calle Uruguay $\mathrm{n}^{\circ} 1980$, \\ C.P 4780000, Temuco, Araucanía, Chile \\ E-mail: pedro.delgado@ufrontera.cl
}

Date of reception: 29-11-2016

Date of acceptance: 04-01-2017

DOI://dx.doi.org/10.24875/GMM.M18000080
Gac Med Mex. 2017;153:706-711

Contents available at PubMed www.gacetamedicademexico.com 
conditions, but there is sparse information that enables validating programs for preoperative treatment, which generates the need for structured interventions to be implemented.

The purpose of this investigation was to assess the effects of a physical exercise program on the lipid profile, the weight status and cardiovascular health of obese candidates to bariatric surgery.

\section{Method}

Twenty-two obese/morbidly obese subjects aged between 18 and 60 years participated voluntarily and were applied a 6-month long physical exercise program with 3 stimuli per week (1 hour per session). Each patient was his/her own control prior and after the intervention. Sixteen subjects formed the adherent group (age: $37.81 \pm 11.90$ years) and six the non-adherent group (age: $45.83 \pm 14.23$ years).

The inclusion criteria established that the patients had to be between 18 and 60 years' old, have a body mass index $(\mathrm{BMI}) \geq 40 \mathrm{~kg} / \mathrm{m}^{2}$ or a BMI $\geq 35 \mathrm{~kg} / \mathrm{m}^{2}$ and comorbidities (type II diabetes mellitus, high blood pressure, dyslipidemia, insulin resistance), medical authorization for the practice of physical exercise, and no participation in previous physical activity programs. An attendance $\geq 80 \%$ of total scheduled sessions was requested.

Exclusion criteria of the research were having physical limitations to practice exercise, presence of respiratory pathologies, chronic heart conditions with any exacerbation, osteomyoarticular system lesions or pathologies that hindered the performance of physical exercise, or decompensated or uncontrolled non-transmittable chronic conditions.

Of the 22 participants who initiated the intervention, 16 met the stipulated requirements and formed the adherent group. The patients with $<80 \%$ participation of total sessions of the program formed the non-adherent group ( $n=6)$; these subjects participated in the program during all months, but irregularly, with $30 \%$ average attendance (22 sessions).

In the research, the Declaration of Helsinki (2013) agreements were observed, and every patient signed an informed consent prior to the study.

The patients were called for one day for pre-intervention assessments. Between 8:00 and 10:00 in the morning, the fasting lipid profile variables and blood pressure were collected; 8 hours later, the weight status variables were measured and the 5 -minute walk test (6MWT) was applied. Final measurements were carried out 72 hours after the last exercise session took place with the same order used at pre-test. All subjects were instructed not to modify their eating habits or physical activity during the intervention.

Weight was determined with a SECA ${ }^{\circledR}$ calibrated mechanical weigh beam scale for adults $(220 \mathrm{~kg})$ with height rod, graduated. The scale was calibrated each time an individual was assessed according to the manufacturer's manual. BMI was determined in order to estimate the degree of obesity. Waist circumference (WC) was measured with a SECA ${ }^{\circledR}$ retractile measuring tape for adults, graduated in centimeters.

The assessment of biochemical parameters was carried out with blood samples collected in tubes without anticoagulant. The samples were centrifuged at $2500 \mathrm{rpm}$ for 10 minutes, in order to obtain the serum to be used. Glucose, total cholesterol, high-density lipoprotein cholesterol (HDL-C), low-density lipoprotein cholesterol (LDL-C) and triglycerides serum concentrations were determined by standard colorimetric methods in a HumaStar80 auto-analyzer. LDL-C concentration was obtained with the Friedwald formula when triglyceride concentration was $<400 \mathrm{mg} / \mathrm{dL}$. The samples were taken and processed by medical technologists at the health centers of each patient with a fasting $\geq 10$ hours.

Blood pressure was measured with the protocol of the clinical guidelines for primary or essential hypertension in 15-year old or older subjects ${ }^{14}$. To assess the cardiorespiratory capacity, the 6MWT was used because it is a tool that is increasingly used in clinical practice, which measures the capability of a subject to perform physical exercise by measuring the maximum distance he/she can walk during 6 minutes. The 6MWT test was carried out in a closed space, on a 30 meter-long plain surface, at the extremes of which two reflecting cones were placed to mark the limit of the route and to allow the morbidly obese subjects to turn by walking around them. Visible marks were placed on the route in order to facilitate the registry of the covered distance. The test was conducted by physical education teachers at between 17:00 and 20:00 hours, and they used motivational phrases that were proposed in the protocol. In a card that was specially designed for the test, personal data, weight and height were recorded. After a 10-minute rest, the test's characteristics were clearly and individually explained. Prior to the 6MWT, at the end of it and 3 minutes later, the respiratory rate, heart rate and oxygen saturation were recorded ${ }^{15}$. 
From six to eight overload exercises of the large muscular groups (forearm flexor and extensor, trunk flexor, pectoral, shoulder elevation, knee extensor and plantiflexor muscles) were applied, with three series been executed for 60 seconds each, with an intensity that induced muscle failure at the end of this period and with a 2-minute pause between series (a methodology called $1 \times 2 \times 3)^{16} ; 2$ to $4 \mathrm{~kg}$ were added weekly, always reaching the exercise time indicated by the method. Each session included a 10-minute warm up consisting of continuous jog, locomotion and joint mobility exercises, lateral movements and elongation. At the end of the main phase, cooling down and stretching was carried out after the session.

All variables were expressed as the mean and standard deviation. The variables' normality was assessed with the Shapiro Wilk test. For variables' comparison prior and after the intervention and between groups, Student's t-test was used for related samples and for independent samples. All analysis were made with the SPSS program, version 23.0. A margin of error of $5 \%$ was used $(p<0.05)$.

\section{Results}

In the adherent group, weight $(p<0.001)$, BMI $(p<0.001)$ and WC $(p=0.001)$ showed significant changes with the physical exercise program. The cardiorespiratory capacity was significantly increased $(9.80 \% ; p=0.001)$. Systolic blood pressure did not show significant changes ( $p \geq 0.05$ ), whereas diastolic pressure $(p=0.011$ ) and basal blood glucose were significantly decreased $(p=0.021)$. In the non-adherent group, weight, BMI and WC were decreased, with statistical significance being reached $(p<0.05)$, but with lower percentage results than those for the adherent group. In the comparison between the adherent and non-adherent groups, there were significant differences only at pre-test BMI $(p<0.05)$ (Table 1).

Table 2 shows that, in the adherent group, triglycerides were significantly decreased by $20.46 \%$ ( $p<0.001$ ); conversely, total cholesterol, HDL-C and LDL-C showed no significant variations $(p \geq 0.05$ ). The non-adherent group showed no significant variations in the lipid profile ( $p \geq 0.05$ ); in addition, their HDL-C was decreased by $12.01 \%$. There were no significant variations in the comparison between groups.

\section{Discussion}

The purpose of this investigation was to assess the effects of a physical exercise program on the lipid profile, weight status and cardiovascular health of obese candidates to bariatric surgery. Since there was no control group, two groups were compared according to their participation in the program; those who failed to meet the attendance percentages were grouped as non-adherent. The most important findings were recorded in the adherent group, where significant reductions were observed in weight $(p<0.001)$, BMI $(p<0.001)$, WC $(p<0.001)$, diastolic blood pressure $(p=0.011)$ and triglycerides $(p<0.001)$, as well as a significant increase in the meters covered in the 6MWT $(p=0.001)$. The non-adherent group showed significant changes only in weight, BMI and WC, but at much lower percentages than those in the adherent group.

The participants were made aware that they should not participate in any other structured exercise protocol and were recommended to maintain their normal patterns during the intervention. With the program, weight did significantly decrease by applying in the patients exercises at intervals. One investigation carried out by Sánchez et al. ${ }^{17}$ reported decreases of $5.17 \mathrm{~kg}$ on average in morbidly obese patients pending surgery by applying a 2-month duration program with moderate intensity exercise. One study performed during 3 months in morbidly obese subjects with comorbidities, in whom interval-wise exercise was applied with a similar methodology to that used in the present investigation, obtained a decrease of 1.41 $\mathrm{kg}^{18}$. When the results of this study were compared with an investigation of equal duration time where aerobic physical exercise was applied, the $5.3 \mathrm{~kg}$ decrease obtained ${ }^{19}$ was lower than the $10.14 \mathrm{~kg}$ reduction reported in this research. Weight loss prior to bariatric surgery is associated with a marked reduction in the risk of postoperative complications ${ }^{20}$ and with morphology and cardiac function improvements, as well as with a reduction of cardiovascular risk factors ${ }^{21}$.

An excess of abdominal and visceral fat mass is considered, in epidemiological studies, as one of the most important risk factors for cardiovascular disease $^{22,23}$, and WC reduction should therefore be an important goal in interventional programs for this type of patients. In the present study, WC was decreased by $8.37 \mathrm{~cm}$ in the adherent group, which improved the 
Table 1. Weight, BMI and WC comparative results

\begin{tabular}{|c|c|c|c|}
\hline & Adherent group & Non-adherent group & $\begin{array}{c}p \\
\text { (between groups) }\end{array}$ \\
\hline \multicolumn{4}{|l|}{ Weight (kg) } \\
\hline Pre-test & $119.05 \pm 23.68$ & $103.05 \pm 9.71$ & 0.128 \\
\hline Post-test & $108.91 \pm 20.28$ & $100.50 \pm 10.15$ & 0.348 \\
\hline Change (\%) & -8.52 & -2.91 & \\
\hline$p$ & $<0.001$ & 0.006 & \\
\hline \multicolumn{4}{|l|}{ BMI $\left(\mathrm{kg} / \mathrm{m}^{2}\right)$} \\
\hline Pre-test & $44.41 \pm 7.71$ & $39.78 \pm 2.16$ & 0.041 \\
\hline Post-test & $40.61 \pm 6.44$ & $38.78 \pm 2.25$ & 0.510 \\
\hline Change (\%) & -8.55 & -2.56 & \\
\hline$p$ & $<0.001$ & 0.007 & \\
\hline \multicolumn{4}{|l|}{ WC (cm) } \\
\hline Pre-test & $131.56 \pm 17.24$ & $123.50 \pm 6.57$ & 0.284 \\
\hline Post-test & $123.19 \pm 12.63$ & $120.67 \pm 6.71$ & 0.650 \\
\hline Change (\%) & -6.37 & -2.43 & \\
\hline$p$ & 0.001 & 0.047 & \\
\hline \multicolumn{4}{|c|}{ Diastolic pressure (mmHg) } \\
\hline Pre-test & $83.00 \pm 8.61$ & $75.33 \pm 5.72$ & 0.070 \\
\hline Post-test & $75.29 \pm 8.13$ & $76.83 \pm 2.99$ & 0.660 \\
\hline Change (\%) & -9.29 & $1.34 \%$ & \\
\hline$p$ & 0.011 & 0.472 & \\
\hline \multicolumn{4}{|c|}{ Systolic pressure (mmHg) } \\
\hline Pre-test & $126.77 \pm 16.20$ & $120.00 \pm 22.92$ & 0.467 \\
\hline Post-test & $121.75 \pm 8.53$ & $126.40 \pm 8.85$ & 0.327 \\
\hline Change (\%) & -3.96 & $5.03 \%$ & \\
\hline$p$ & 0.312 & 0.590 & \\
\hline \multicolumn{4}{|l|}{ 6MWT (m) } \\
\hline Pre-test & $568.57 \pm 52.27$ & $577.50 \pm 73.74$ & 0.760 \\
\hline Post-test & $624.29 \pm 77.16$ & $615.83 \pm 100.52$ & 0.839 \\
\hline Change (\%) & 9.80 & 6.60 & \\
\hline$p$ & 0.001 & 0.181 & \\
\hline \multicolumn{4}{|c|}{ Basal blood glucose (mg/dL) } \\
\hline Pre-test & $100.93 \pm 15.19$ & $94.50 \pm 4.14$ & 0.326 \\
\hline Post-test & $95.29 \pm 11.96$ & $93.67 \pm 3.39$ & 0.751 \\
\hline Change (\%) & -5.60 & 1.08 & \\
\hline$p$ & 0.021 & 0.259 & \\
\hline
\end{tabular}

BMI: body mass index; WC: waist circumference; 6MWT: 6-minute walk test.

conditions and health of participants, with these results being similar to those reported in an investigation conducted in female candidates to bariatric surgery $(7.57 \mathrm{~cm})^{24}$, and to those of a lifestyle intervention in morbidly obese subjects that implied diet combined with physical activity and that obtained favorable changes in cardiometabolic risk factors ${ }^{24}$. Therefore, physical activity promotes a higher reduction in WC and hepatic fat content.

Diastolic blood pressure was significantly reduced, but systolic pressure did not reach significance, although it had a decrease of $3.96 \%$, in comparison with a 6-month aerobic exercise program that yielded significant changes in systolic $(-23.8 \pm 27.7 \mathrm{mmHg}$; $p<0.0001)$ and diastolic blood pressure $(-14.4 \pm$ $8.9 \mathrm{mmHg} ; \mathrm{p}<0.0001)^{19}$. One-year long interventions with nutritional counseling and changes in physical activity have shown positive results in these study variables ${ }^{26}$, thus improving cardiovascular health of participants with excess-malnutrition.

Cardiorespiratory capacity significantly increased by $9.80 \%$, which is an important variation, since it is associated with lower cardiometabolic risk ${ }^{27}$. In 4-month duration studies with multidisciplinary approach, the 
Table 2. Comparison (median and standard deviation) of triglycerides, total cholesterol, HDL-C and LDL-C

\begin{tabular}{|c|c|c|c|}
\hline & Adherent group & Non-adherent group & $\begin{array}{c}\mathrm{p} \\
\text { (between groups) }\end{array}$ \\
\hline \multicolumn{4}{|c|}{ Triglycerides (mg/dL) } \\
\hline Pre-test & $145.44 \pm 59.49$ & $122.37 \pm 25.63$ & 0.711 \\
\hline Post-test & $115.69 \pm 52.35$ & $116.50 \pm 25.84$ & 0.570 \\
\hline Change (\%) & -20.46 & $3.34 \%$ & \\
\hline$p$ & $<0.001$ & 0.365 & \\
\hline \multicolumn{4}{|c|}{ Total cholesterol (mg/dL) } \\
\hline Pre-test & $180.87 \pm 43.12$ & $180.33 \pm 20.15$ & 0.851 \\
\hline Post-test & $175.80 \pm 37.53$ & $177.80 \pm 22.30$ & 0.661 \\
\hline Change (\%) & -2.80 & $-1.66 \%$ & \\
\hline$p$ & 0.602 & 0.364 & \\
\hline \multicolumn{4}{|l|}{$\mathrm{HDL}-\mathrm{C}(\mathrm{mg} / \mathrm{dL})$} \\
\hline Pre-test & $43.63 \pm 10.07$ & $50.67 \pm 20.92$ & 0.239 \\
\hline Post-test & $45.00 \pm 9.91$ & $44.00 \pm 7.40$ & 0.825 \\
\hline Change (\%) & 3.15 & $-12.01 \%$ & \\
\hline p & 0.423 & 0.410 & \\
\hline \multicolumn{4}{|l|}{ LDL-C (mg/dL) } \\
\hline Pre-test & $113.31 \pm 41.60$ & $134.33 \pm 67.75$ & 0.626 \\
\hline Post-test & $109.59 \pm 38.85$ & $131.33 \pm 67.93$ & 0.088 \\
\hline Change (\%) & -3.29 & -2.23 & \\
\hline$p$ & 0.602 & 0.229 & \\
\hline
\end{tabular}

HDL-C: high-density lipoprotein cholesterol; LDL-C: low-density lipoprotein cholesterol.

distance covered in the 6MWT was increased by $7.17 \%{ }^{28}$. On the other hand, an 8-week interventional protocol with high-intensity exercise and overload exercise at intervals significantly improved the aerobic physical performance of women with and without metabolic alterations ${ }^{29}$.

In the metabolic profile, basal blood glucose showed a $5.60 \%$ decrease, which is similar to other investigations in sedentary women with overweight and obesity who were applied high-intensity exercises ${ }^{30}$, but lower to reports in other groups of morbidly obese subjects ${ }^{24,31}$. In the lipid profile, triglycerides showed a significant decrease of $20.46 \%$, whereas total cholesterol, HDL-C and LDL-C had no significant variations, which are similar results to those described in other investigations ${ }^{24}$. Studies with a duration of 6 and 12 months with diet control and physical exercise produced metabolic parameter decreases in subjects with obesity and morbid obesity ${ }^{25,32}$; therefore, lifestyle interventions with structured physical exercise can be regarded as the morbid obesity treatment mainstay.

In conclusion, the program offers benefits for the treatment of this condition, without adverse effects for the participants' health, and it is feasible owing to the low costs it entails. For future investigations, increasing the number of participants and comparing methods with different work intensities would be desirable.

\section{References}

1. Myers $M$, Leibel $R$, Seeley $R$, et al. Obesity and leptin resistance: distinguishing cause from effect. Trends Endocrinol Metab 2010;21: 643-51.

2. Morton G, Schwartz M. Leptin and the central nervous system control of glucose metabolism. Physiol Rev. 2011;91:389-411.

3. Kushner RF. Weight loss strategies for treatment of obesity. Prog Cardiovasc Dis. 2014;56:465-72.

4. Melanson KJ, Mclnnis KJ, Rippe JM, et al. Obesity and cardiovascular disease risk: research update. Cardiol Rev. 2001;9:202-7.

5. Dallongeville $\mathrm{J}$, Bringer $\mathrm{J}$, Bruckert $\mathrm{E}$, et al. Abdominal obesity is associated with ineffective control of cardiovascular risk factors in primary care in France. Diabetes Metab. 2008:34:606-11.

6. Calle EE, Thun MJ. Obesity and cancer. Oncogene. 2004;23:6365-78.

7. Muñoz M, Mazure R, Culebras J. Obesidad y sistema inmune. Nutr Hosp. 2004;19:319-24.

8. Karamouzis I, Pervanidou P, Berardelli R, et al. Enhanced oxidative stress and platelet activation combined with reduced antioxidant capacity in obese prepubertal and adolescent girls with full or partial metabolic syndrome. Horm Metab Res. 2011;43:607-13.

9. Fontaine KR, Redden DT, Wang C, et al. Years of life lost due to obesity. JAMA. 2003;289:187-93.

10. Ruano M, Silvestre V, Aguirregoicoa E, et al. Nutrición, síndrome metabólico y obesidad mórbida. Nutr Hosp. 2011;26:759-64.

11. MINSAL. Encuesta Nacional de Salud 2009-2010. Santiago: Ministerio de Salud de Chile; 2010.

12. Ocón J, Pérez S., Gimeno S, et al. Eficacia y complicaciones de la cirugía bariátrica en el tratamiento de la obesidad mórbida. Nutr Hosp. 2005; 20:409-14.

13. Lanzarini E, Marambio A, Fernández L, et al. Hiperobesidad y obesidad mórbida: estudio comparativo. Rev Chil Cir. 2012;64:233-7.

14. MINSAL. Guía clínica de hipertensión arterial primaria o esencial en personas de 15 años y más. Santiago: Ministerio de Salud de Chile; 2010.

15. Gatica D, Puppo H, Villarroel G, et al. Valores de referencia del test de marcha de seis minutos en niños sanos. Rev Méd Chile. 2012;140:1014-21.

16. Saavedra C. Guía de actividad física para el adulto mayor. Santiago: Instituto Nacional del Deporte; 2006. 
17. Sánchez L, Sánchez C, García A. Valoración de un programa de ejercicio físico estructurado en pacientes con obesidad mórbida pendientes de cirugía bariátrica. Nutr Hosp. 2014;29:64-72.

18. Delgado $P$, Jerez $D$, Caamaño $F$, et al. Doce semanas de ejercicio físico intervalado con sobrecarga mejora las variables antropométricas de obesos mórbidos y obesos con comorbilidades postulantes a cirugía bariátrica. Nutr Hosp. 2015;32:2007-11.

19. Marcon E, Gus I, Neumann C. Impacto de um programa mínimo de exercícios físicos supervisionados no risco cardiometabólico de pacientes com obesidade mórbida. Arq Bras Endocrinol Metab. 2011:55:331-8.

20. Anderin C, Gustafsson UO, Heijbel N, et al. Weight loss before bariatric surgery and postoperative complications: data from the Scandinavian Obesity Registry (SOReg). Ann Surg. 2015;261:909-13.

21. Rueda-Clausen CF, Ogunleye AA, Sharma AM. Health benefits of longterm weight-loss maintenance. Annu Rev Nutr. 2015;35:475-516.

22. Despres JP, Lemieux I, Bergeron J, et al. Abdominal obesity and the metabolic syndrome: contribution to global cardiometabolic risk. Arterioscler Thromb Vasc Biol. 2008;28:1039-49.

23. Sung RY, Yu CC, Choi KC, et al. Waist circumference and body mass index in Chinese children: cutoff values for predicting cardiovascular risk factors. Int J Obes (Lond). 2007;31:550-8.

24. Delgado $\mathrm{P}$, Jerez D, Caamaño F, et al. Efectividad del tratamiento integral sobre las condiciones preoperatorias de mujeres obesas candidatas a cirugía bariátrica. Nutr Hosp. 2015;32:2570-5.
25. Goodpaster BH, Delany JP, Otto AD, et al. Effects of diet and physical activity interventions on weight loss and cardiometabolic risk factors in severely obese adults: a randomized trial. JAMA. 2010;304:1795-802.

26. Unick J, Beavers D, Jakicic J, et al. Effectiveness of lifestyle interventions for individuals with severe obesity and type 2 diabetes results from the look AHEAD trial. Diabetes Care. 2011;34:2152-7.

27. Díez-Fernández A, Sánchez-López M, Mora-Rodríguez R, et al. Obesity as a mediator of the influence of cardiorespiratory fitness on cardiometabolic risk: a mediation analysis. Diabetes Care. 2014;37:855-62.

28. Delgado $\mathrm{P}$, Cofré $\mathrm{A}$, Alarcón $\mathrm{M}$, et al. Evaluación de un programa integral de cuatro meses de duración sobre las condiciones preoperatorias de pacientes obesos candidatos a cirugía bariátrica. Nutr Hosp. 2015;32:1022-7.

29. Álvarez C, Ramírez-Campillo R, Henríquez-Olguín C, et al. ¿Pueden ocho semanas de ejercicio físico combinado normalizar marcadores metabólicos de sujetos hiperglicémicos y dislipidémicos? Rev Méd Chile. 2014;142:458-66.

30. Álvarez C, Ramírez R, Flores M, et al. Efectos del ejercicio físico de alta intensidad y sobrecarga en parámetros de salud metabólica en mujeres sedentarias, pre-diabéticas con sobrepeso u obesidad. Rev Méd Chile. 2012;140:1289-96.

31. Delgado $P$, Caamaño F, Jerez D, et al. Efectos de un programa de tratamiento multidisciplinar en obesos mórbidos y obesos con comorbilidades candidatos a cirugía bariátrica. Nutr Hosp. 2015;31:2014-9.

32. Miller CT, Fraser SF, Straznicky NE, et al. Effect of diet versus diet and exercise on weight loss and body composition in class ii and iii obesity: a systematic review. J Diabetes Metab. 2013;4:1-6. 